\title{
The Adequacy of a Conventional Mechanical Ventilator as a Ventilation Method during Cardiopulmonary Resuscitation: A Manikin Study
}

\author{
Hong Joon Ahn, M.D. , Kun Dong Kim, M.D., Won Joon Jeong, M.D., Jun Wan Lee, M.D., \\ In Sool Yoo, M.D., and Seung Ryu, M.D.
}

Department of Emergency Medicine; *Intensivist of Regional Emergency Medical Center, College of Medicine, Chungnam National University Hospital, Daejeon, Korea

Background: We conducted this study to verify whether a mechanical ventilator is adequate for cardiopulmonary resuscitation (CPR). Methods: A self-inflating bag resuscitator and a mechanical ventilator were used to test two experimental models: Model 1 (CPR manikin without chest compression) and Model 2 (CPR manikin with chest compression). Model 2 was divided into three subgroups according to ventilator pressure limits $\left(\mathrm{P}_{\text {limit }}\right)$. The self-inflating bag resuscitator was set with a ventilation rate of $10 \mathrm{breaths} / \mathrm{min}$ with the volume-marked bag-valve procedure. The mode of the mechanical ventilator was set as follows: volume-controlled mandatory ventilation of tidal volume $(\mathrm{Vt}) 600 \mathrm{~mL}$, an inspiration time of 1.2 seconds, a constant flow pattern, a ventilation rate of 10 breaths/ minute, a positive end expiratory pressure of $3 \mathrm{cmH}_{2} \mathrm{O}$ and a maximum trigger limit. Peak airway pressure $\left(\mathrm{P}_{\text {peak }}\right)$ and Vt were measured by a flow analyzer. Ventilation adequacy was determined at a Vt range of $400-600 \mathrm{~mL}$ with a $\mathrm{P}_{\text {peak }}$ of $\leq 50 \mathrm{cmH}_{2} \mathrm{O}$.

Results: In Model 1, Vt and $P_{\text {peak }}$ were in the appropriate range in the ventilation equipments. In Model 2 , for the self-inflating bag resuscitator, the adequate $V t$ and $P_{\text {peak }}$ levels were $17 \%$, and the $P_{\text {peak }}$ adequacy was $20 \%$ and the $V t$ was $65 \%$. For the mechanical ventilator, the adequate $\mathrm{Vt}$ and $\mathrm{P}_{\text {peak }}$ levels were $85 \%$; the $\mathrm{P}_{\text {peak }}$ adequacy was $85 \%$; and the $\mathrm{Vt}$ adequacy was $100 \%$ at $60 \mathrm{cmH}_{2} \mathrm{O}$ of $\mathrm{P}_{\text {limit }}$.

Conclusions: In a manikin model, a mechanical ventilator was superior to self-inflating bag resuscitator for maintaining adequate ventilation during chest compression.

Key Words: cardiopulmonary resuscitation; peak airway pressure; pressure limit; self-inflating bag resuscitator; tidal volume; ventilator.

\section{Introduction}

Although ventilation plays an important role in high quality cardiopulmonary resuscitation (CPR), it is difficult to perform appropriate ventilation during CPR.[1-3] To address this problem, studies for preventing excessive ventilation have been conducted using simple methods such as a metronome, thoracic impedance, capnography, and tracheal pressure monitoring.[4-8] However, it is difficult to maintain a proper tidal volume $(\mathrm{Vt})$ and ventilation rate with a self-inflating bag resuscitator during CPR. One study on actual CPR showed that use of a self-inflating bag resuscitator is likely to result in excessive ventilation

Received on January 20, 2015 Revised on April 27, 2015 Accepted on April 27, 2015

Correspondence to: Seung Ryu, Department of Emergency Medicine, College of Medicine, Chungnam National University Hospital, 282 Munhwa-ro, Jung-gu, Daejeon 301-721, Korea

Tel: +82-42-280-8007, Fax: +82-42-280-8082

E-mail: rs0505@cnuh.co.kr

*No potential conflict of interest relevant to this article was reported. and high airway pressure in practice,[9] whereas using an automatic transport ventilator instead of a self-inflating bag resuscitator shows better outcomes.[10-12]

Despite various efforts, the study of ventilation during CPR has not provided adequate evidence on ventilation rate, $\mathrm{Vt}$, or peak airway pressure $\left(\mathrm{P}_{\text {peak }}\right)$. Moreover, when unexpected cardiac arrest occurs in patients, no studies or guidelines direct 
the use of a mechanical ventilator. We conducted this study to determine whether the use of a mechanical ventilator during $\mathrm{CPR}$ is adequate to maintain the ventilation rate, $\mathrm{Vt}$, and $\mathrm{P}_{\text {peak }}$.

\section{Materials and Methods}

\section{1) Experimental protocol and data collection}

We conducted this study at a tertiary teaching hospital from March 2013 to May 2013.

One manual self-inflating bag resuscitator (Ambu ${ }^{\circledR}$ Resuscitator Mark IV, Ambu, Ballerup, Denmark), and 1 mechanical ventilator were used in Model 1 (CPR manikin without compression) and Model 2 (CPR manikin with compression).

A CPR manikin (Resusci Anne Skill ReporterTM, Laerdal, Stavanger, Norway), which allows the evaluation of the adequacy of $\mathrm{CPR}$, was connected to a flow analyzer by a 7.0 mm endotracheal tube and a 1-way valve (Fig. 1).

With a self-inflating bag resuscitator, we performed ventilation at 10 breaths/min and used the volume-marked bagvalve procedure[13] to control Vt. The mechanical ventilator (MV2500 SU:M3, MEK-ICS CO., Seongnam, Korea) was used under the same conditions for volume-controlled mandatory ventilation: Vt $600 \mathrm{~mL}$, inspiration time (Ti) 1.2 sec, constant flow pattern, ventilation rate 10 breaths $/ \mathrm{min}$, and positive end expiratory pressure (PEEP) $3 \mathrm{cmH}_{2} \mathrm{O}$. We set the triggering limit to maximum and divided the pressure limit $\left(\mathrm{P}_{\text {limit }}\right)$ into 3 subgroups to test Model $2\left(\mathrm{P}_{\text {limit }}: 40\right.$, $50,60 \mathrm{cmH}_{2} \mathrm{O}$ ). We used a flow analyzer (Flowanalyser ${ }^{\mathrm{TM}}$

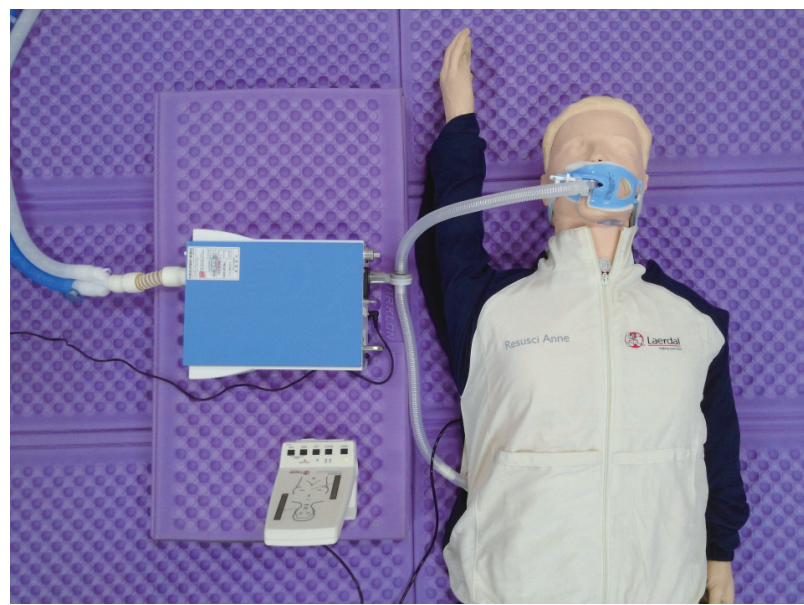

Fig. 1. Closed loop manikin circuit connected to flow analyzer.
PF-300, Imtmedical, Switzerland) to measure $\mathrm{P}_{\text {peak }}$ and Vt in each group. Ventilation was considered adequate when $\mathrm{Vt}$ was in the range of 400-600 mL[14-16] and $P_{\text {peak }}$ was $\leq 50$ $\mathrm{cmH}_{2} \mathrm{O}$.

Chest compression was performed by 4 emergency medicine residents on the floor, and ventilation was performed by 1 emergency medicine resident; all residents were certified advanced cardiac life support providers. A total of 10 minutes of chest compressions were used in each subgroup, and chest compression depth $(5-6 \mathrm{~cm})$ and rate $(100 / \mathrm{min})$ were maintained, as verified by a skilled reporter. The ventilation (10 breaths/min) was verified by the flow analyzer. The 4 chest compression performers took 2-minute turns to reduce the effect of performer fatigue.

\section{2) Statistical analysis}

We used the Kruskal-Wallis test to compare the continuous variables; each value represented the median value and quartile. We used the $\chi 2$ test or Fisher's exact test to analyze the discrete variables. PASW 18.0 (SPSS Inc., Chicago, IL, USA) was used to compile statistics, and the significance level was $\mathrm{p}<0.05$.

\section{Results}

\section{1) Comparison between the ventilation equipment used on the manikin}

Compliance and resistance were $35 \mathrm{~mL} / \mathrm{cmH}_{2} \mathrm{O}$ and 20 $\mathrm{cmH}_{2} \mathrm{O} / \mathrm{L} / \mathrm{sec}$, respectively, with the manikin prepared as shown in Fig. 1. Ventilation equipment $\mathrm{Vt}$ and $\mathrm{P}_{\text {peak }}$ were in an appropriate range (Table 1).

\section{2) Comparison between the ventilation equipment during chest compression (Table 1 and Fig. 2)}

When a self-inflating bag resuscitator was used during chest compression, an adequate $\mathrm{Vt}$ and $\mathrm{P}_{\text {peak }}$ were observed at $17 \%$. When an adequate $\mathrm{Vt}$ was maintained, $\mathrm{P}_{\text {peak }}$ over 50 $\mathrm{cmH}_{2} \mathrm{O}$ was $48 \%$.

A mechanical ventilator with CPR produced the following results: With $\mathrm{P}_{\text {limit }}$ set at $40 \mathrm{cmH}_{2} \mathrm{O}$, it was possible to maintain $\mathrm{P}_{\text {peak }}$ at $94 \%$ and $\mathrm{Vt}$ at $42 \%$; an adequate $\mathrm{Vt}$ and $\mathrm{P}_{\text {peak }}$ level was $37 \%$. With $\mathrm{P}_{\text {limit }}$ set at $50 \mathrm{cmH}_{2} \mathrm{O}$, it was possible to maintain $\mathrm{P}_{\text {peak }}$ at $79 \%$ and $\mathrm{Vt}$ at $100 \%$; an adequate $\mathrm{Vt}$ and $\mathrm{P}_{\text {peak }}$ level was $79 \%$. With $\mathrm{P}_{\text {limit }}$ set at $60 \mathrm{cmH}_{2} \mathrm{O}$, it was pos- 
Table 1. Comparison of median value (IQR) between the ventilation equipment used on the manikin in Model 1 (CPR Manikin without compression)

\begin{tabular}{lcc}
\hline Type of ventilation & Tidal volume $(\mathrm{mL})$ & Peak airway pressure $\left(\mathrm{cmH}_{2} 0\right)$ \\
\hline Resuscitator $(n=100)$ & $613.50(599.00-620.00)$ & $23.15(22.00-24.77)$ \\
Ventilator $(n=100)$ & $559.5(556.00-565.00)$ & $25.75(25.60-25.90)$ \\
\hline
\end{tabular}

Resuscitator; self-inflating bag resuscitator, Ventilator; mechanical ventilator.
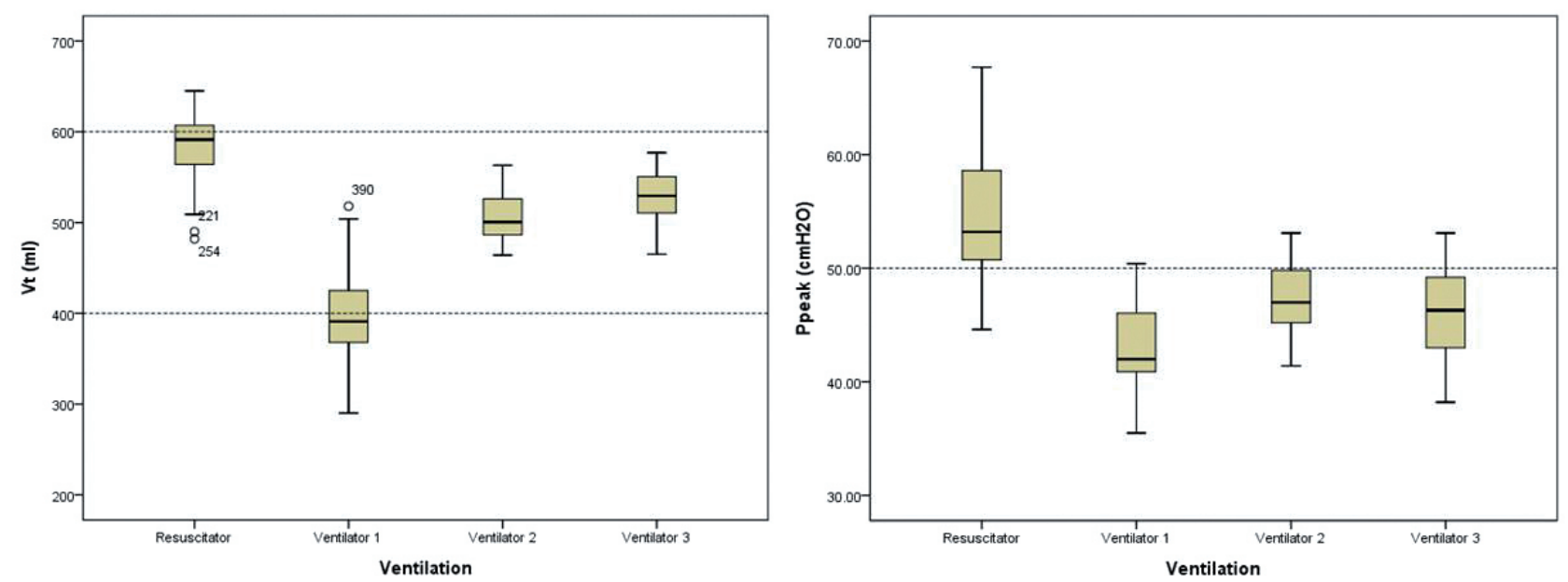

Fig. 2. Changes of the tidal volume and peak airway pressure in Model 2. Model 2; CPR Manikin with compression, Resuscitator; selfinflating bag resuscitator, ventilator 1; $\mathrm{P}_{\text {limit }} 40 \mathrm{cmH}_{2} 0,2 ; \mathrm{P}_{\text {limit }} 50 \mathrm{cmH}_{2} \mathrm{O}, 3 ; \mathrm{P}_{\text {limit }} 60 \mathrm{cmH}_{2} \mathrm{O}$, Tidal volume adequacy; Vt $400-600 \mathrm{~mL}$, Peak airway pressure adequacy; $P_{\text {peak }} \leq 50 \mathrm{cmH}_{2} \mathrm{O}$, Adequate ventilation; Vt $400-600 \mathrm{~mL}$ and $P_{\text {peak }} \leq 50 \mathrm{cmH}_{2} 0$.

sible to maintain $\mathrm{P}_{\text {peak }}$ at $85 \%$ and $\mathrm{Vt}$ at $100 \%$; an adequate Vt and $\mathrm{P}_{\text {peak }}$ level was $85 \%$.

\section{Discussion}

In its 2010 guidelines, the American Heart Association (AHA) suggested that high-quality CPR should maintain a rate of at least 100 compressions/min and a compression depth of at least 2 inches $(5 \mathrm{~cm})$ in adults to allow complete chest recoil after each compression, minimize interruption in chest compression, and prevent excessive ventilation. The AHA also advised that CPR should be performed at the rate of 8-10 breaths/min, allowing $400-600 \mathrm{~mL}$ of ventilation without interruption of chest compression when an endotracheal tube is inserted.[17] Despite those guidelines on ventilation, proper ventilation has not yet been clearly set. Despite many studies, the effort to determine an optimal $\mathrm{Vt}$ and ventilation rate has been unsuccessful.[18,19] Meanwhile, the more hyperventilation occurs during CPR, the more positive pressure is created, leading to increased intrathoracic pressure, $[9,20]$ which could decrease survival rates by reducing venous return, cardiac output, and coronary perfusion pressure.[21-23] Those side effects in hemodynamics tend to be caused by changes in the ventilation rate rather than changes in Vt.[9, 24-27] Therefore, guidelines based on recent studies suggest reduced Vt, compared with the past, and a restricted ventilation rate.

According to a study by Aufderheide et al.,[22] rescuers consistently hyperventilated patients during pre-hospital CPR, and subsequent animal studies showed that mean intrathoracic pressure increased from $7.1 \pm 0.7 \mathrm{mmHg} / \mathrm{min}$ to $17.5 \pm 1.0 \mathrm{mmHg} / \mathrm{min}$ when the ventilation rate increased from 12 breaths/min to 30 breaths/min during CPR. To solve this problem, a real-time audiovisual feedback system that maintains the ventilation rate at a certain level has been suggested for use with a self-inflating bag resuscitator. However, although a self-inflating bag resuscitator with an additional device could control the ventilation rate, it might not control Vt. The volume-marked bag-valve procedure, 
Table 2. Comparison among the ventilation equipment during chest compression in model 2 (CPR Manikin with compression)

\begin{tabular}{|c|c|c|c|c|c|c|}
\hline \multirow{2}{*}{ Type of ventilation } & \multicolumn{2}{|c|}{ Tidal volume } & \multicolumn{2}{|c|}{ Peak airway pressure } & \multicolumn{2}{|c|}{ Adequate ventilation } \\
\hline & Adequacy (\%) & $p$-value & Adequacy (\%) & $\mathrm{p}$-value & Adequacy (\%) & $\mathrm{p}$-value \\
\hline Resuscitator $(n=100)$ & 65 & $<0.001$ & 20 & $<0.001$ & 17 & $<0.001$ \\
\hline \multicolumn{7}{|l|}{ Ventilator } \\
\hline$P_{\text {limit }} 40 \mathrm{cmH}_{2} \mathrm{O}(n=100)$ & 42 & & 94 & & 37 & \\
\hline$P_{\text {limit }} 50 \mathrm{cmH}_{2} \mathrm{O}(n=100)$ & 100 & & 79 & & 79 & \\
\hline $\mathrm{P}_{\text {limit }} 60 \mathrm{cmH}_{2} \mathrm{O}(\mathrm{n}=100)$ & 100 & & 85 & & 85 & \\
\hline
\end{tabular}

Resuscitator; self-inflating bag resuscitator, Ventilator; mechanical ventilator

Tidal volume adequacy; Vt 400-600 mL, Peak airway pressure adequacy; $\mathrm{P}_{\text {peak }} \leq 50 \mathrm{cmH}_{2} \mathrm{O}$

Adequate Ventilation; Vt 400-600 mL and $\mathrm{P}_{\text {peak }} \leq 50 \mathrm{cmH}_{2} \mathrm{O}$.

p-value was analyzed by Chi-square or Fischer's exact test.

Table 3. Comparison of median value (IQR) among the ventilation equipment during chest compression in model 2 (CPR Manikin with compression)

\begin{tabular}{|c|c|c|}
\hline Type of ventilation & Tidal volume (mL) & Peak airway pressure $\left(\mathrm{cmH}_{2} \mathrm{O}\right)$ \\
\hline Resuscitator $(n=100)$ & 591.50 (563.50 - 607.00) & $53.20(50.73-58.75)$ \\
\hline \multicolumn{3}{|l|}{ Ventilator } \\
\hline $\mathrm{P}_{\text {limit }} 40 \mathrm{cmH}_{2} \mathrm{O}(\mathrm{n}=100)$ & $391.00(368.00-425.50)$ & $42.00(40.90-46.08)$ \\
\hline$P_{\text {limiti }} 50 \mathrm{cmH}_{2} \mathrm{O}(n=100)$ & $500.50(486.25-526.00)$ & $47.00(45.20-49.85)$ \\
\hline $\mathrm{P}_{\text {llimit6 }} 60 \mathrm{cmH}_{2} \mathrm{O}(\mathrm{n}=100)$ & $529.50(510.25-550.75)$ & $46.30(42.90-49.20)$ \\
\hline
\end{tabular}

Resuscitator; self-inflating bag resuscitator, Ventilator; mechanical ventilator

which we used in this study, could solve that problem, but its effectiveness has not yet been proved, and that is beyond the scope of this study. In fact, it is not easy to simultaneously obtain a certain level of $\mathrm{Vt}$ and $\mathrm{P}_{\text {peak }}$ with a self-inflating bag resuscitator.

For this reason, we determined whether a mechanical ventilator might be used during $C P R$ to maintain ventilation rate, $\mathrm{Vt}$, and stable intrathoracic pressure. We found that when volume-controlled mandatory ventilation was set at Vt $600 \mathrm{~mL}$, Ti $1.2 \mathrm{sec}$, constant flow type, ventilation rate 10 breaths/min, PEEP $3 \mathrm{cmH}_{2} \mathrm{O}$, maximum pressure triggering, and $\mathrm{P}_{\text {limit }} 60 \mathrm{cmH}_{2} \mathrm{O}, \mathrm{Vt}$ and $\mathrm{P}_{\text {peak }}$ retained relatively high adequacy, as compared with the other subgroups of the mechanical ventilator and the self-inflating bag resuscitator. According to Maertens et al.,[8] the ventilation rate was higher than the setting when a transport ventilator was used because the chest compression caused assisted ventilation from the flow triggering. Therefore, we set the triggering limit to its maximum to prevent assisted ventilation.

In a real situation, very high $\mathrm{P}_{\text {peak }}$ was observed as a result of hyperventilation, suggesting a higher risk of barotrauma. In this context, it is necessary to set an adequate $\mathrm{P}_{\text {limit }}$ to prevent barotrauma when proper $\mathrm{Vt}$ is guaranteed. In Model 2 , the self-inflating bag resuscitator $\mathrm{P}_{\text {limit }}$ median value was $53.2 \mathrm{cmH}_{2} \mathrm{O}$ (IQR 50.73-58.75), and the mechanical ventilator was $46.3 \mathrm{cmH}_{2} \mathrm{O}$ (IQR 42.90-49.20) with a $\mathrm{P}_{\text {limit }}$ of $60 \mathrm{cmH}_{2} \mathrm{O}$ (Table 3). We suggest that a $\mathrm{P}_{\text {limit }}$ of $60 \mathrm{cmH}_{2} \mathrm{O}$ is adequate to prevent barotrauma.

The manikin we used showed lower compliance and higher resistance than a normal human being, which might be a limitation to this study. Compliance was lower because the manikin's artificial lung was stiff, and resistance was higher because the length of the circuit was longer than a human airway. In a human airway, inspiration and expiration occur through the same lumen, whereas we used separated lumens in this study. An adequate mechanical ventilator mode for human CPR needs to be identified in further studies. However, this study showed that the adequacy of $\mathrm{Vt}$ and $\mathrm{P}_{\text {peak }}$ using a mechanical ventilator was higher than that using a self-inflating bag resuscitator in CPR. Moreover, it is difficult to maintain $\mathrm{Vt}$ and $\mathrm{P}_{\text {peak }}$ during CPR when using a self-inflating bag resuscitator because excessive Vt or insufficient Vt occur often.[2,9] We suggest that a mechanical ventilator set to the proper mode can provide steadier and 
more stable ventilation than a self-inflating bag resuscitator. In our manikin model, the mechanical ventilator was superior to the self-inflating bag resuscitator for maintenance of adequate ventilation during chest compression. Using a mechanical ventilator that can maintain adequate $\mathrm{Vt}$ and ventilation rate can prevent excessive ventilation. A mechanical ventilator that can maintain $\mathrm{P}_{\text {peak }}<50 \mathrm{cmH}_{2} \mathrm{O}$ can also prevent barotrauma.

Although we found differences according to the $\mathrm{P}_{\text {limit, }}$, we conclude that a mechanical ventilator might be used to achieve high quality CPR in patients with endotracheal intubation.

\section{ORCID}

Hong Joon Ahn http://orcid.org/0000-0001-6809-6246

Kun Dong Kim http://orcid.org/0000-0002-7635-0942

Won Joon Jeong http://orcid.org/0000-0002-6320-230X

Jun Wan Lee $\quad$ http://orcid.org/0000-0003-4630-597X

In Sool Yoo http://orcid.org/0000-0003-3685-4561

Seung Ryu http://orcid.org/0000-0003-0748-2543

\section{References}

1) McInnes AD, Sutton RM, Orioles A, Nishisaki A, Niles $\mathrm{D}$, Abella BS, et al: The first quantitative report of ventilation rate during in-hospital resuscitation of older children and adolescents. Resuscitation 2011; 82: 1025-9.

2) Aufderheide TP, Lurie KG: Death by hyperventilation: a common and life-threatening problem during cardiopulmonary resuscitation. Crit Care Med 2004; 32(9 Suppl): S345-51.

3) Park SO, Shin DH, Baek KJ, Hong DY, Kim EJ, Kim $\mathrm{SC}$, et al: A clinical observational study analysing the factors associated with hyperventilation during actual cardiopulmonary resuscitation in the emergency department. Resuscitation 2013; 84: 298-303.

4) Kern KB, Stickney RE, Gallison L, Smith RE: Metronome improves compression and ventilation rates during CPR on a manikin in a randomized trial. Resuscitation 2010; 81: 206-10.

5) Abella BS, Edelson DP, Kim S, Retzer E, Myklebust
H, Barry AM, et al: CPR quality improvement during in-hospital cardiac arrest using a real-time audiovisual feedback system. Resuscitation 2007; 73: 54-61.

6) Edelson DP, Litzinger B, Arora V, Walsh D, Kim S, Lauderdale DS, et al: Improving in-hospital cardiac arrest process and outcomes with performance debriefing. Arch Intern Med 2008; 168: 1063-9.

7) Edelson DP, Eilevstjønn J, Weidman EK, Retzer E, Hoek TL, Abella BS: Capnography and chest-wall impedance algorithms for ventilation detection during cardiopulmonary resuscitation. Resuscitation 2010; 81: 317-22.

8) Maertens VL, De Smedt LE, Lemoyne S, Huybrechts SA, Wouters K, Kalmar AF, et al: Patients with cardiac arrest are ventilated two times faster than guidelines recommend: an observational prehospital study using tracheal pressure measurement. Resuscitation 2013; 84: 921-6.

9) O’Neill JF, Deakin CD: Do we hyperventilate cardiac arrest patients? Resuscitation 2007; 73:82-5.

10) Weiss SJ, Ernst AA, Jones R, Ong M, Filbrun T, Augustin $\mathrm{C}$, et al: Automatic transport ventilator versus bag valve in the EMS setting: a prospective, randomized trial. South Med J 2005; 98: 970-6.

11) Johannigman JA, Branson RD, Johnson DJ, Davis K Jr, Hurst JM: Out-of-hospital ventilation: bag--valve device vs transport ventilator. Acad Emerg Med 1995; 2: 719-24.

12) Salas N, Wisor B, Agazio J, Branson R, Austin PN: Comparison of ventilation and cardiac compressions using the Impact Model 730 automatic transport ventilator compared to a conventional bag valve with a facemask in a model of adult cardiopulmonary arrest. Resuscitation 2007; 74: 94-101.

13) Cho YC, Cho SW, Chung SP, Yu K, Kwon OY, Kim SW: How can a single rescuer adequately deliver tidal volume with a manual resuscitator? An improved device for delivering regular tidal volume. Emerg Med J 2011; 28: 40-3.

14) Wenzel V, Keller C, Idris AH, Dörges V, Lindner KH, Brimacombe JR: Effects of smaller tidal volumes during basic life support ventilation in patients with respiratory arrest: good ventilation, less risk? Resuscitation 1999; 43: 25-9. 
15) Dörges V, Ocker H, Hagelberg S, Wenzel V, Idris AH, Schmucker P: Smaller tidal volumes with room-air are not sufficient to ensure adequate oxygenation during bag-valve-mask ventilation. Resuscitation 2000; 44: 37 41.

16) Dörges V, Ocker H, Hagelberg S, Wenzel V, Schmucker P: Optimisation of tidal volumes given with self-inflatable bags without additional oxygen. Resuscitation 2000; 43: 195-9.

17) Neumar RW, Otto CW, Link MS, Kronick SL, Shuster M, Callaway CW, et al: Part 8: adult advanced cardiovascular life support: 2010 American Heart Association Guidelines for Cardiopulmonary Resuscitation and Emergency Cardiovascular Care. Circulation 2010; 122(18 Suppl 3): S729-67.

18) Langhelle A, Sunde K, Wik L, Steen PA: Arterial bloodgases with 500- versus 1000-ml tidal volumes during out-of-hospital CPR. Resuscitation 2000; 45: 27-33.

19) Dorph E, Wik L, Steen PA: Arterial blood gases with $700 \mathrm{~mL}$ tidal volumes during out-of-hospital CPR. Resuscitation 2004; 61: 23-7.

20) Yannopoulos D, Aufderheide TP, Gabrielli A, Beiser DG, McKnite SH, Pirrallo RG, et al: Clinical and hemodynamic comparison of 15:2 and 30:2 compressionto-ventilation ratios for cardiopulmonary resuscitation. Crit Care Med 2006; 34: 1444-9.

21) Yannopoulos D, Sigurdsson G, McKnite S, Benditt D, Lurie KG: Reducing ventilation frequency combined with an inspiratory impedance device improves CPR efficiency in swine model of cardiac arrest. Resuscitation 2004; 61: 75-82

22) Aufderheide TP, Sigurdsson G, Pirrallo RG, Yannopoulos D, McKnite S, von Briesen C, et al: Hyperventilation-induced hypotension during cardiopulmonary resuscitation. Circulation 2004; 109: 1960-5.

23) Yannopoulos D, Tang W, Roussos C, Aufderheide TP, Idris AH, Lurie KG: Reducing ventilation frequency during cardiopulmonary resuscitation in a porcine model of cardiac arrest. Respir Care 2005; 50: 628-35.

24) Deakin CD, Nolan JP, Soar J, Sunde K, Koster RW, Smith GB, et al: European Resuscitation Council Guidelines for Resuscitation 2010 Section 4. Adult advanced life support. Resuscitation 2010; 81: 1305-52.

25) Theres H, Binkau J, Laule M, Heinze R, Hundertmark $\mathrm{J}$, Blobner $\mathrm{M}$, et al: Phase-related changes in right ventricular cardiac output under volume-controlled mechanical ventilation with positive end-expiratory pressure. Crit Care Med 1999; 27: 953-8.

26) Karlsson T, Stjernström EL, Stjernström H, Norlén K, Wiklund L: Central and regional blood flow during hyperventilation. An experimental study in the pig. Acta Anaesthesiol Scand 1994; 38: 180-6.

27) Cheifetz IM, Craig DM, Quick G, McGovern JJ, Cannon ML, Ungerleider RM, et al: Increasing tidal volumes and pulmonary overdistention adversely affect pulmonary vascular mechanics and cardiac output in a pediatric swine model. Crit Care Med 1998; 26: 710-6. 